
\title{
3 Research Square \\ Pollution Characteristics and Emissions of Typical Organophosphate Esters From a Wastewater Treatment Plant in Chengdu, China
}

Hongling Yin ( $\sim$ belling15@126.com )

Chengdu University of Information Technology https://orcid.org/0000-0002-1662-4673

Yi Luo

Chengdu University of Information Technology

Jiaojiao Song

Chengdu University of Information Technology

Shiping Li

Chengdu University of Information Technology

Shuyu Lin

Chengdu University of Information Technology

Yuanming Xiong

Chengdu University of Information Technology

Shuhong Fang

Chengdu University of Information Technology

Juan Tang

Chengdu University of Information Technology

\section{Research Article}

Keywords: Organophosphate esters, wastewater treatment plant, rainy period, pollution characteristics, removal, emissions

Posted Date: August 24th, 2021

DOI: https://doi.org/10.21203/rs.3.rs-801402/v1

License: (c) (i) This work is licensed under a Creative Commons Attribution 4.0 International License.

Read Full License 


\section{Abstract}

Effluent from wastewater treatment plants (WWTP) is an important source of organophosphate esters (OPEs) in the receiving rivers. In this paper, the concentration and distribution of seven OPEs in the water samples were determined, and the discharge was estimated. The results showed that the total removal rate of $\Sigma_{7}$ OPEs in water phase in WWTP was $57.2 \%$. The average concentrations of $\Sigma_{7}$ OPEs in influent and effluent of the WWTP during rainy period were $3956.1 \pm 1897.3 \mathrm{ng} / \mathrm{L}$ and $1461.9 \pm 846.3 \mathrm{ng} / \mathrm{L}$, respectively, which were about 4 times larger than those in influent water $(978.2 \pm 166.5 \mathrm{ng} / \mathrm{L})$ and effluent $(418.3 \pm 12.0 \mathrm{ng} / \mathrm{L})$ during non-rainy period, indicating that rainfall has a marked impact on the load of OPEs in WWTP and the receiving water. It was estimated that the average daily discharge of $\Sigma_{7}$ OPEs in the effluent of WWTP was $157.9 \mathrm{~g}$, and the daily per capita contribution of the population in the area to the OPEs in the influent was $0.414 \mathrm{mg}$. During the shift of labour-intensive manufacturing from the coastal developed areas to inland regions, OPEs were widely used and produced in Southwest China. The total amount of OPEs emissions and its control should be taken into consideration.

\section{Introduction}

In recent years, organophosphate esters (OPEs) have been produced and consumed in large quantities as they are an alternative to brominated flame retardants (Gao et al., 2015). As a major producer of OPEs, the average annual output of OPEs in China was expected to maintain a growth rate of more than $11 \%$ (Zhang et al., 2012). However, it is easy for OPEs to enter the environment through volatilization, product wear, leakage and other ways in the process of production, transportation and use, because OPEs was added in the material by physical addition rather than chemical bonding (Gao et al., 2014). At present, OPEs widely existed in water (Kim et al., 2018; Yin et al., 2021), soil (Yin et al., 2016; Yang et al., 2018), outdoor air (Yin et al., 2020; Javier et al., 2016) and indoor (Tan et al., 2017) environment, even in many kinds of animals and plants (Wan et al., 2017; Strobel et al., 2018), human urine (Schindler et al., 2009) and breast milk (Sundkvist et al., 2010). Unfortunately, previous studies have demonstrated that some OPEs have the characteristics of carcinogenesis, neurotoxicity and reproductive toxicity that may bring risks to human health (Kim et al., 2018).

OPEs has been detected in rivers and lakes in many countries, such as Taihu in China (Wang et al., 2018), Nanjing section of the Yangtze River, China (Li et al., 2019), Rhine River in Germany (Bollmann et al., 2012), tributaries of Lake Michigan in the United States (Guo et al., 2017), etc. The discharge of industrial and domestic sewage is considered as the major source of OPEs in surface water (Reemtsma et al., 2006). In Sweden, the concentrations of chlorophosphates in the effluent of the three WWTPs were all at the level of $\mu \mathrm{g} / \mathrm{L}$ (Nicklas et al., 1996). Another investigation indicated tris-(2-butoxyethyl) phosphate (TBEP) and Tributyl Phosphate (TBP) were the main substances of 12 kinds of OPEs in the influent and effluent of 11 WWTPs in Sweden, followed by TCPP (Marklund et al., 2005). In all the OPEs, $49 \%$ of them were degraded, $50 \%$ of them were discharged into the receiving water, and chlorinated organic phosphate could not be effectively removed or degraded after treatment (Marklund et al., 2005). In Germany, TBEP 
and TCPP were the main substances in the influent and effluent of two WWTPs, of which the degradation rate of TBEP was 78-94\%, while chlorinated OPEs were difficult to degrade (Meyer et al., 2004). Similarly, TBEP had been found to be the main pollutant in WWTPs in the United States (Kim et al., 2017), Austria (Reemtsma et al., 2006), Australia (O'Brien et al., 2015) and other countries. In China, The concentration of $\sum_{14}$ OPEs in the influent and effluent of a WWTP in Beijing was $1399 \pm 263 \mathrm{ng} / \mathrm{L}, 833 \pm 175 \mathrm{ng} / \mathrm{L}$, respectively, and the removal rate of $\sum_{14} \mathrm{OPEs}$ in the aqueous phase was $40.5 \%$. The activated sludge treatment system with anaerobic/anoxic/aerobic bioreactor was the main process to remove OPEs (Liang et al., 2016). TBP (21271.8 ng/L) and TBEP (4349.4 ng/L) were the most abundant compounds of OPEs in the wastewater samples of a WWTP in the Pearl River Delta, China. The concentrations of three chlorinated OPEs (TCEP, TCPP and TDCPP) were $438.2 \mathrm{ng} / \mathrm{L}, 299.0 \mathrm{ng} / \mathrm{L}$ and $60.3 \mathrm{ng} / \mathrm{L}$, respectively. TBP $(3105.1 \mathrm{ng} / \mathrm{L})$ and TBEP (494.5 ng/L) were still the main components in the effluent (Zhang et al., 2015). It was found that the concentration of $\sum_{6}$ OPEs in influent was $1106.5 \mu \mathrm{g} / \mathrm{L}$ and in effluent was 511.7 $\mu \mathrm{g} / \mathrm{L}$ in the mixed water samples of a WWTP in Zhengzhou, Henan Province, China (Pang et al., 2016). In Hefei, the concentration of $\Sigma_{9}$ OPE was $1102.24 \mathrm{ng} / \mathrm{L}$ in the influent of a WWTP, in which TCEP (546.69 $\mathrm{ng} / \mathrm{L})$, TCPP (324.42 ng/L), TBEP (91.98 ng/L) were the primary pollutants. Chlorinated OPEs could not be effectively removed (Zhao et al., 2018). In general terms, OPEs have been detected in treated and untreated wastewater (Reemtsma et al., 2006), wastewater-impacted surface waters (Andresen et al., 2004; Weigel et al., 2005), and groundwater affected by surface water (Prsch et al., 2002; Thomas et al., 2004). Treated and untreated wastewater discharges were presumed to be the main entry pathway for OPEs to surface waters and impacted groundwater, Researchers reported the concentrations of OPEs in them often exceed the acceptable concentration $(0.1 \mu \mathrm{g} / \mathrm{L})$ proposed by the Federal Environmental Agency of Germany (Bester, 2006).

Atmosphere deposition has been pointed to be another important source of OPEs in surface water (Regnery and Püttmann, 2009). Limited studies reported the pollution level and the increasing load of OPEs in the road runoff during the rainfall (Gnecco et al., 2005; Hou et al., 2012; Lee et al., 2002; Perdikaki et al., 1999; Ren et al., 2008; Taebi and Droste, 2004). Study indicated that volatilization of OPEs from objects protected by flame retardants, including vehicles and buildings, causes these compounds to reach the aquatic environment via concentration washout from the atmosphere. Higher OPEs concentrations were observed in urban precipitation (Bacaloni et al., 2008; Marklund et al., 2005) suggesting that emissions from urban settlements and road traffic are the dominant sources of OPEs in the atmosphere. Gromaire et al. (2001) evaluated the contribution of different sources such as runoff, sanitary sewage and sewer sediments to the total wet weather pollutant loads over 31 rain events in central Paris and found that the erosion of in-sewer pollutant stocks was the main source of particles and of organic matter. To our knowledge, few limited studies were focused on the differences of pollution characteristics and load of OPEs in WWTP and the receiving water between rainy period and non-rainy period.

The present work is aimed at: (1) quantifying the seven OPEs compounds in the influent water, effluent water and receiving water of a WWTP in Chengdu, China; (2) comparing the concentration level, 
distribution characteristics and removal efficiency of OPEs in each treatment unit of the WWTP between the rainy and non-rainy period; (3) evaluating the discharge of OPEs and the possible impact of rain on the load of WWTP and the external environment. The results would fill the gaps of the blank of OPEs pollution data both in non-rainy period and rainy period in WWTP in Southwest China and shine a light on further control of organic pollution in water environment in rainy period.

\section{Materials And Methods}

\section{Chemicals}

The main reagents including ethyl acetate, acetone, hexane and acetonitrile were high performance liquid chromatography (HPLC) grade (Kelon Che-mical Co., China). The standard solut-ion (Sigma Aldrich, USA) included t-ri-n-butyl phosphate (TnBP), tris-(2-e-thylhexyl) phosphate (TEHP), tris-(2-butoxyethyl) phosphate (TBEP), triphe-nyl phosphate (TPhP), tris-(2-chloroet-hyl) phosphate (TCEP), tris-(2-chloroisopropyl) phosphate (TCPP), and tri-s-(2.3-dichloropropyl) phosphate (TDCPP). Copper, aluminium oxide, silic-a gel, $\mathrm{Na}_{2} \mathrm{SO}_{4}$ and other chemicals w-ere purchased from Kelon Chemical Co.. Deionized water was supplied fr-om a Milli-Q equipment.

\section{Study area and sample collection}

Chengdu is a typical inland city located in the southwest of China. It is the capital and megacity of Sichuan Province, which covers an area of 14335 square kilometers and has a permanent population of 16.33 million. Our previous studies have shown that the concentration of OPEs in various environmental media in Chengdu was relatively high, and the local source was the main source (Yin et al., 2015; 2016).

Samples were collected from a WWTP in Chengdu, which processes about $168000 \mathrm{~m}^{3}$ of municipal sewage every day and serves about 1 million people. The influent water of the WWTP comes from the municipal pipe network, and the new pipe network has been divided into rainwater and sewage. However, the old pipe network does not have the rainwater and sewage diversion. During rainy period, the rainwater, road runoff and other scouring water would be mixed. The UCT-MBR (University of Capetown-Membrane Bioreactor) secondary biological treatment process was used in the WWTP. The sewage firstly flows through the coarse grid, then into the fine grid through the lifting pump. After that, it enters the biochemical reaction pool through the lifting pump room, goes into the membrane pool after treatment, and finally discharges into the river through the ultraviolet disinfection channel. The treatment tanks in the plant are all semi-closed/closed tanks, which would not be affected by rainfall during the treatment process. During rainy period, water samples and dewatered sludge were collected three times a day $(10: 30,16: 00$ and 21:00), with $1 \mathrm{~L}$ samples each time on September 4, September 24 and October 25, 2019. $24 \mathrm{H}$ rainwater samples were collected three times from September to October using a stainless steel sampler located on top of the Chengdu University of Information Technology. 3L rainwater sample was collected each time and divided into two parallel samples. During non-rainy period, a total of 8 samples of inlet and outlet water (without rainfall) were collected from June 18, July 2 and November 12, 
13 (all without rainfall), 2019. Concentrations of OPEs were compared to see whether the concentration level and distribution of OPEs in municipal pipe network inflow and outflow were relatively stable. At the same time, it also proved whether the samples collected on different dates had good representative and typicality. On November 12 and 13, 2019, every 4h samples were collected with $200 \mathrm{~mL}$ water samples of each process section (influent, before biochemical treatment, after biochemical treatment, before UV treatment, effluent) and dewatered sludge. Then $24 \mathrm{~h}$ water samples were mixed. Water samples were collected 100 meters from the upstream and downstream of the receiving water during each sampling period. The main process and sampling sites in WWTP were shown in Fig. 1.

Sample preparation and analysis

After the water sample was collected, the $0.45 \mu \mathrm{m}$ microporous filter membrane was used for filtration, and then enriched by the $\mathrm{C} 18$ column (silica gel). After the water sample passed through the column, the column was firstly eluted with $10 \mathrm{~mL}$ hexane to remove impurities, then with $20 \mathrm{~mL}$ ethyl acetate: acetone (4:3/v:v) and the eluate (ethyl acetate/acetone) was collected. The eluent was dehydrated with anhydrous sodium sulphate and transferred to the concentration bottle, concentrated by vacuumcondensing equipment (Buchi Syncore Q-101, Switzerland) to nearly dry. The eluent was transferred to the sample bottle and diluted to $200 \mu \mathrm{L}$ for gas chromatography-mass spectrometry (GC-MS) (Shimadzu 2010plus, Japan) analysis.

The GC is equipped with a capillary column Rti-5MS $(30 \mathrm{~m} \times 0.25 \mu \mathrm{m} \times 0.25 \mathrm{~mm})$, with a $280{ }^{\circ} \mathrm{C}$ inlet temperature using splitless injection. The MS source was electron impact (EI) and operated in selected ion monitoring (SIM) mode. Helium was used as a carrier gas with a flow rate of $1.00 \mathrm{~mL} / \mathrm{min}$. The GC oven temperature was held at $50{ }^{\circ} \mathrm{C}$ for 1 minute, increased to $200{ }^{\circ} \mathrm{C}$ at $15^{\circ} \mathrm{C} / \mathrm{min}$ and held for 1 minute, increased to $250{ }^{\circ} \mathrm{C}$ at $4.00{ }^{\circ} \mathrm{C} / \mathrm{min}$, and then increased to $260{ }^{\circ} \mathrm{C}$ at $20^{\circ} \mathrm{C} / \mathrm{min}$ and held for 4 minutes. The interface temperature was $280^{\circ} \mathrm{C}$, and the ion source temperature was $200{ }^{\circ} \mathrm{C}$. The respective characteristic ion and reference ions $(\mathrm{m} / \mathrm{z})$ of the 7 target compounds were: 155/99, 211, 125 (TnBP), 249/63, 143, 251 (TCEP), 125/99, 201, 277, 157 (TCPP), 75/99, 191, 209, 381 (TDCPP), 326/325, 77, 215 (TPhP), 85/100, 199, 299 (TBEP), 99/113 and 211 (TEHP).

Quality assurance/quality control (QA/QC)

Thorough QA/QC procedures for OPE analysis were conducted to ensure data quality. The concentrations of the seven OPEs compounds were determined by an external standard method. To evaluate the recovery efficiencies of analytical procedures, all samples were added with internal standard (TDCPP- $\mathrm{d}_{15}$ and TPhP- $\mathrm{d}_{15}$ ), and the accuracy was evaluated by their recoveries. The mixed standard solutions with concentrations of $0.05 \mathrm{mg} / \mathrm{L}, 0.10 \mathrm{mg} / \mathrm{L}, 0.50 \mathrm{mg} / \mathrm{L}, 1.00 \mathrm{mg} / \mathrm{L}$ and $2.00 \mathrm{mg} / \mathrm{L}$ were measured. The correlation coefficients of the standard curves of the seven OPE monomers were all greater than 0.990 and the recoveries of the seven OPEs and the internal standard ranged from $70.5 \%$ to $115.4 \%$. Procedural contamination from the analytical steps aforementioned was evaluated by running a matrix blank with every batch of 10 samples. Only TnBP and TCEP were detected in the blanks, and the levels were $<5 \%$ of 
the concentrations measured in all samples, which means they were negligible. The instrument precision was in the range of $1.9-8.3 \%$.

\section{Results And Discussion}

\section{Levels of OPEs}

As shown in Fig. 2, the range of $\sum_{7}$ OPEs concentration in the influent water from WWTP was 811.7$1144.7 \mathrm{ng} / \mathrm{L}$. With the sewage entering each treatment process, the differences of $\sum_{7} \mathrm{OPES}$ concentrations become smaller. The $\sum_{7} \mathrm{OPEs}$ concentrations in inlet and outlet water samples in the four sampling days were tested by SPSS software, respectively. Results showed that $p=0.083>0.05$ for the influent samples and $p=0.082>0.05$ for the effluent samples, indicating that there is no significant difference in the $\sum_{7} \mathrm{OPEs}$ concentrations in the inlet or outlet water of the WWTP. So the concentration level and distribution of OPEs in the influent and effluent of the WWTP are relatively stable. The samples collected in different dates in this study have good representative and typicality.

The range of total concentration ( $\Sigma_{7}$ OPEs) in the WWTP was 406.3-1144.7 ng/ $\mathrm{L}$, in which the concentration of OPEs in influent was $978.2 \pm 166.5 \mathrm{ng} / \mathrm{L}$ while in the effluent was $418.3 \pm 12.0 \mathrm{ng} / \mathrm{L}$ (Fig. 3). The average concentration of $\sum_{7} \mathrm{OPEs}$ in dewatered sludge collected in non-rainy period was $1066.2 \pm 91.5 \mathrm{ng} / \mathrm{g}$. The concentration of OPEs in the downstream of the receiving water was $325.9 \pm$ $58.45 \mathrm{ng} / \mathrm{L}$, which was about 1.5 times that in the upstream $(222.2 \pm 25.4 \mathrm{ng} / \mathrm{L})$, but lower than that in the effluent of the WWTP. This confirmed that the discharge of WWTP is an important source of OPEs in the receiving water, which was similar with the result from Rodgers et al. (2018) who estimated that loadings of $\Sigma_{6}$ OPEs to Lake Ontario from WWTP, streams and atmospheric deposition were $70 \%, 18 \%$ and $13 \%$, respectively by using an updated multimedia urban model (MUM).

When compared with the data of OPEs in WWTP from the United States, Sweden, Austria, Germany and other developed countries or regions (Kim et al., 2017; Marklund et al., 2005; Reemtsma et al., 2006; Quintana et al., 2006), it was found that the levels of $\Sigma_{7}$ OPEs in effluent in this study was relatively low. Compared with the data of OPEs in the effluent from WWTP in China, $\Sigma_{7}$ OPEs concentration in this study was lower than that in a WWTP from the Pearl River Delta ( $\Sigma_{7}$ OPEs, 494.5-3105.1 ng/L) (Zhang et al., 2015), a WWTP in Henan ( $\Sigma_{6}$ OPEs, $511.7 \mu \mathrm{g} / \mathrm{L}$ ) (Pang et al., 2016) and seven WWTPs in Suzhou $\left(\Sigma_{7} \mathrm{OPEs} \llbracket 62.43 \mu \mathrm{g} / \mathrm{L}\right)\left(\right.$ Sun, 2018), but higher than that of WWTP in Beijing $\left(\Sigma_{8} \mathrm{OPEs}, 162.5 \mathrm{ng} / \mathrm{L}\right)$ (Liang et al., 2016).

The average concentration of $\Sigma_{7}$ OPEs in the water samples of each treatment unit was in the order of $A$ (influent) > B (before biochemical treatment) > C (after biochemical treatment) > D (before UV)> $E$ (effluent). However, the level of $\Sigma_{7} \mathrm{OPEs}$ in the effluent was relatively consistent with that before UV, which suggested that the UV disinfection channel of WWTP failed to remove OPEs.

\section{Composition profile of OPEs}


The detection frequencies of all target OPEs in all samples were 100\%. It can be seen from Fig. 4 that the distribution of OPEs in the effluent of each unit in WWTP was similar, which was in the order of TBEP $(34 \%)>\operatorname{TDCPP}(29 \%)>\operatorname{TCPP}(12 \%)>\operatorname{TCEP}(10 \%)>\operatorname{TnBP}(9 \%)>\operatorname{TPhP}(4 \%)>\operatorname{TEHP}(2 \%)$. The primary pollutants in WWTP were TBEP $(134.4 \pm 27.1 \mathrm{ng} / \mathrm{L})$ and TDCPP $(396.0 \pm 99.4 \mathrm{ng} / \mathrm{L})$. This was consistent with the report from Rodgers et al. (2018) that WWTPs were the largest pathways for TCPP, TDCPP and TBEP, while stream loadings were larger for TCEP, TPhP and EHDPP. In this study, the concentrations of chlorinated, alkyl and aryl phosphates accounted for $51 \%, 45 \%$ and $4 \%$ of the $\Sigma_{7}$ OPEs, respectively, which indicated chlorinated and alkyl phosphates were primary OPEs. This differed from the results from other WWTPs where the priority pollutants were only chlorinated organic phosphates, such as the concentrations of chlorinated (TCPP, TCEP and TDCPP) accounted for $88.9 \%$ of the total concentration in a WWTP of Beijing (Liang et al., 2016) and the proportion of chlorinated phosphates reached $80 \%$ except for that in the influent in a WWTP of Hefei, China.

In this study, the composition of OPEs in the upstream and downstream of the receiving water was similar to that in the effluent, and the variation of OPEs in the downstream water was smaller than that in the upstream.

The OPEs composition profile in sludge was TBEP $(39 \%)>\operatorname{TCPP}(28 \%)>\operatorname{TDCPP}(16 \%)>\operatorname{TEHP}(7 \%)>$ $\operatorname{TPhP}(6 \%)>\operatorname{TCEP}(5 \%)>\operatorname{TnBP}(<1 \%)$. TnBP has strong water solubility (lgKow $=4.0)$ and good removal effect in WWTP, so its concentration did not significantly increase in sludge. The water solubility of chlorinated OPEs is poor, in which TCEP (IgKow $=1.44)$ is the lowest, followed by TCPP (IgKow = 2.54), TDCPP (IgKow = 3.65). They are easier to adsorb in sludge, resulting in the proportion of chlorinated OPEs in sludge was much higher than that in water. The proportion of TCEP in water or mud was small, which indicated that the restriction of TCEP in Europe and America also has some influence on the production and use of TCEP in China.

\section{Removal of OPEs in WWTPs}

The total removal rate of $\Sigma_{7}$ OPEs was $57.2 \%$ (Fig. 5), whereas the removal rate of individual compound was in the order of $\operatorname{TnBP}(79.9 \%)>\operatorname{TDCPP}(74.9 \%)>\operatorname{TPhP}(50.4 \%)>\operatorname{TBEP}(44.3 \%)>\operatorname{TCEP}(22.4 \%)>$ TEHP (22.2\%) > TCPP (1.5\%). TCPP was almost not removed (Fig. 6). The removal rate of TnBP and TDCPP in the treatment process of WWTP was over $70 \%$, while the removal of TBEP was almost stable, whereas that of TPhP and TCPP was significant variable. It is hard to remove TCPP and TCEP because they were difficult to be biodegraded, which was consistent with the results from most WWTPs.

The highest removal rate appeared at the grid unit, by which TnBP and TDCPP was effectively removed. The low concentration of TnBP in sludge indicates that sludge adsorption is not the main way to remove TnBP. TnBP was mainly used in synthetic rubber and cellulose acetate as plasticizer, while TDCPP was more widely used in foam (Gao et al., 2016). After passing through coarse and fine grids, aeration grit chamber and membrane grids, the reduction of fine particles may result in the high removal rate of TnBP and TDCPP. Notably, after the treatment of biochemical reaction tank and membrane tank, the 
concentration of chlorinated organic phosphate increased a lot, which may be correlated with the difficulty of biodegradation of chlorinated organic phosphate esters. TDCPP, TCPP and TCEP were difficult to biodegrade, resulting in high level in activated sludge and released into the water. This may also be related to the types of membrane materials and the presence of chlorinated organic phosphates in microorganisms loaded on the membrane.

Although UV has a certain removal effect on OPEs in laboratory researches, it needs strict conditions, such as the content of hydroxyl radicals in water, light intensity and time, etc. (Ai., 2013). Some studies have shown that OPEs could not be effectively removed by ultraviolet light alone. In our study, the difference between the concentration of $\Sigma_{7}$ OPEs in the effluent and the water before UV irradiation was less than $10 \%$, indicating that the UV disinfection channel has little effect on the degradation of OPEs in the sewage.

\section{Impact of rainfall on WWTP and receiving rivers}

During rainy period, the levels of $\Sigma_{7}$ OPEs in studied WWTPs ranged in 512.7-6494.4 ng/L, in which the concentrations of $\Sigma_{7}$ OPEs in the influent was $3956.1 \pm 1897.3 \mathrm{ng} / \mathrm{L}$, while $1461.9 \pm 846.3 \mathrm{ng} / \mathrm{L}$ in the effluent, and the removal rate of $\Sigma_{7}$ OPEs was $63.0 \%$. The concentration of OPEs in the downstream of receiving water was $1201.5 \pm 735.7 \mathrm{ng} / \mathrm{L}$, which was about 3.7 times that in the non-rainy period. Therefore, the OPEs load of WWTP and the receiving water increased significantly in rainy period, which was about four times of that in non-rainy period. This was similar with that Jing et al. (2012) reported that in rainy period, the pollution level of $\mathrm{SS}, \mathrm{COD}, \mathrm{NH}_{3}-\mathrm{N}$ and organic materials in receiving water increased by $16.9-541.7 \%$.

In our study, the concentration of $\sum_{7}$ OPEs in rainwater was $198.5 \pm 30.9 \mathrm{ng} / \mathrm{L}$, which was lower than that in the receiving water, the influent and effluent of the WWTP. Thus the rainwater itself was not the contributor for the increasing load of the WWTP. This was similar with the reported data of the median TCPP level $(743 \mathrm{ng} / \mathrm{L})$ in rainwater being about 2.5 times lower than the median concentrations of TCPP (1575 ng/L and $1607 \mathrm{ng} / \mathrm{L}$, respectively) in the influent and effluent of two WWTP in the Frankfurt area (Regnery and Püttmann, 2009). Though rain can effectively remove the OPEs of gas phase and particle phase in the air (Rodgers et al., 2018), it was found that the OPEs contained in the rainwater will not obviously increase the concentration of OPEs in WWTP. The fact that the concentration of OPEs in the influent and effluent of WWTP during rainy period being much higher than that during non-rainy period meant that the road runoff had a great impact on the OPEs load of WWTP which can brought road dust, dust on canopy, topsoil, other sewage water, etc. into the municipal pipe network by rainwater. Wei et al. (2015) and Shi et al. (2016) all confirmed that road runoff was one of the sources of OPEs in wastewater. Zhang et al. (2014) found that the organic pollutants in the road runoff mainly sourced from vehicles activities and road material. Liu et al. (2018) reported that rainfall accounted for a significant portion of organochlorine pesticides in runoff, and the contribution of canopy through fall water cannot be neglected. It is noteworthy that the field survey in this study suggested that the sewage from some small workshops near the WWTP was directly washed in by the rainfall who would contribute much to the 
higher load of the OPEs during rainy period because they did not implement the rain and sewage diversion as the standard large-scale plants do. It was suggested to identify the sources of OPEs in the road runoff during rainy period.

The ratio of the average concentrations of $\Sigma_{7} \mathrm{OPEs}$ in each treatment unit during rainy and non-rainy period was 4.0, 6.1, 3.5, 3.5, 3.5 for site A (influent), B, C, D and E (effluent), respectively. This result suggested that the load of OPEs were much higher at all treatment units in WWTP. The biochemical reaction pool digests the high load impact brought by rainfall, resulted that the follow-up processing unit $(C, D, E)$ can stably process OPEs and the concentration ratio of OPEs between the rainy and the non-rainy period were consistent at unit $\mathrm{C}, \mathrm{D}$ and $\mathrm{E}$.

As to the dewatered sludge, the average concentration of $\Sigma_{7}$ OPEs in dewatered sludge collected in rainfall period was $1228.1 \pm 209.4 \mathrm{ng} / \mathrm{g}$, which was about 1.2 times of that in non-rainy period $(1066.2 \pm 91.5$ $\mathrm{ng} / \mathrm{g})$. Statistical test showed that there was no significant difference between them $(p>0.05)$, which suggested that the concentration of $\Sigma_{7}$ OPEs in dewatered sludge was less affected by rainfall.

Obvious differences of OPEs profile in WWTP were also observed between the rainy and non-rainy period. During rainy period, the dominated OPEs were TnBP (454.46-1930.85 ng/L, $51 \%$ of $\left.\Sigma_{7} \mathrm{OPEs}\right)$, TBEP (585.68-1052.52 ng/L, $25 \%$ of $\Sigma_{7}$ OPEs) and TDCPP (143.09-608.25 ng/L, $14 \%$ of $\Sigma_{7}$ OPEs). After biochemical treatment, the high concentration of TnBP and TDCPP decreased significantly and the proportion of each OPEs compound in the next three treatment units was similar, with TBEP > TnBP > TDCPP > TCEP > TCPP > TPhP > TEHP. It was found that the composition profile of OPEs was similar in rainwater and receiving water, so does the OPEs in receiving water and effluent of WWTP in rainy period. This indicated that the OPEs in the downstream was greatly affected by the effluent from WWTP and further confirmed that the effluent from WWTP is an important source of OPEs to the river.

Interestingly, TnBP has the most variable concentration between rainy and non-rainy period. The contribution of TnBP in the influent during rainy period was as high as $51 \%$, whereas it decreased sharply to $14 \%$ during non-rainy period. Considered the level and proportion of TnBP in the rainwater, the high concentration of TnBP in the influent of WWTP during rainy period was not due to the rainwater itself, but related to the substances brought by the rain. Apart from being used as flame retardant, TnBP is also used as plasticizer, lubricant, pore regulator, high-carbon alcohol defoamer, as well as in antistatic agents and extractants of rare earth elements. The main downstream products of TnBP are leather finishing agent, interior wall coating, direct blue 86 and cerium carbonate. Among these products, direct blue 86 is mainly used for dyeing and direct printing of cotton and viscose fabrics; cerium carbonate is mainly used for preparing rare earth luminescent materials, automobile exhaust purification catalyst, polishing materials and colors for color engineering plastics; defoamer is mainly used for ink, paint, dye, paint, detergent, adhesive, etc. TnBP has a short atmospheric half-life $(<2 \mathrm{~h})$ indicating the local source of TnBP. In the study area, there are many industrial sources such as leather finishing agent, dye, adhesive and so on, as well as there are many motor vehicles, so the content of TnBP was high. 
In rainy period, the removal rate of $\Sigma_{7}$ OPEs was $63.1 \%$, higher than non-rainy period (57.2\%). The biochemical reaction pool had the highest removal efficiency, which can remove $50 \%$ of OPEs, mainly because the biochemical pool was added with flocculant PAC. This was consistant with the result from that some OPEs can be effectively removed after aerobic, anoxic and anaerobic treatment (Liang et al., 2016; Sun et al., 2018). The removal rate of individual compound was in the order of $\operatorname{TnBP}(76.5 \%) \approx$ $\operatorname{TDCPP}(76.5 \%)>\operatorname{TEHP}(46.6 \%)>\operatorname{TBEP}(44.4 \%)>\operatorname{TPhP}(28.1 \%)>\operatorname{TCPP}(24.4 \%)>\operatorname{TCEP}(16.0 \%)$. Interestingly, due to the contribution of grid and UV irradiation units, the remove rate of TCPP increased from $1.5 \%$ (non-rainy period) to $24.4 \%$ (rainy period). In our study, the difference between the concentration of $\Sigma_{7}$ OPEs in the effluent and the water before UV irradiation was less than $10 \%$, indicating that the UV disinfection channel has little effect on the degradation of OPEs in the sewage. But in rainy period, the remove rate of TCPP by UV irradiation was $12 \%$ which was obviously improved from that in the non-rainy period $(\sim 0)$. Therefore, the mechanism of the remove of OPEs by UV irradiation in rainy period needs further study. How to improve the ability of ultraviolet disinfection channel to degrade OPEs and other organic pollutants in the effluent was worth thinking.

\section{Emission estimation of OPEs from WWTP}

The average daily treatment capacity of the WWTP is about $168000 \mathrm{~m}^{3}$, and the WWTP serves 1 million people. Assuming that the inlet flow was constant during the day, the daily receiving amount and daily discharge amount of $\Sigma_{7}$ OPEs along with the inflow and outflow were calculated. The results were shown in Table 1. During non-rainy period, the daily emission of $\Sigma_{7} \mathrm{OPEs}$ was $70.3 \mathrm{~g}$, and the annual emission was $25.6 \mathrm{~kg}$. The daily emissions of primary pollutants were TBEP $(25.9 \mathrm{~g})$, TDCPP $(16.5 \mathrm{~g})$ and TCPP $(10.9 \mathrm{~g})$. During rainy period, the load of OPEs in the sewage treatment plant and the receiving water were increased. The daily emission of $\Sigma_{7}$ OPE was $245.6 \mathrm{~g}$ and the annual emission of $89.6 \mathrm{~kg}$. TBEP $(98.4 \mathrm{~g})$, $\operatorname{TnBP}(76.3 \mathrm{~g})$ and TDCPP $(24.0 \mathrm{~g})$ contributed much of the emissions per day.

Table 1 Daily acceptance and discharge of OPEs in a WWTP in Chengdu /g

\begin{tabular}{|llllllllll|}
\hline $\begin{array}{l}\text { Sampling } \\
\text { period }\end{array}$ & $\begin{array}{l}\text { Estimated } \\
\text { quantity }\end{array}$ & TnBP & TCEP & TCPP & TDCPP & TPhP & TBEP & TEHP & $\sum_{7}$ OPEs \\
\hline $\begin{array}{l}\text { Rainy } \\
\text { period }\end{array}$ & $\begin{array}{l}\text { Receiving } \\
\text { capacity }\end{array}$ & 324.4 & 23.9 & 19.8 & 102.2 & 12.9 & 176.8 & 4.6 & 664.6 \\
\cline { 2 - 5 } & Emissions & 76.3 & 20.1 & 15.0 & 24.0 & 9.3 & 98.4 & 2.4 & 245.6 \\
\hline $\begin{array}{l}\text { Non-rainy } \\
\text { period }\end{array}$ & $\begin{array}{l}\text { Receiving } \\
\text { capacity }\end{array}$ & 22.6 & 10.7 & 11.1 & 66.5 & 5.2 & 46.6 & 1.8 & 164.3 \\
\cline { 2 - 8 } & Emissions & 4.5 & 8.3 & 10.9 & 16.7 & 2.6 & 25.9 & 1.4 & 70.3 \\
\hline Average reception & 173.5 & 17.3 & 15.4 & 84.4 & 9.0 & 111.7 & 3.2 & 414.5 \\
\hline Average emissions & 40.4 & 14.2 & 12.9 & 20.4 & 5.9 & 62.2 & 1.9 & 157.9 \\
\hline
\end{tabular}


Concentration of the same targets of OPEs in the three-stage effluent from a WWTP in Beijing was 661.8 $\mathrm{ng} / \mathrm{L}$, whose sewage treatment capacity was about $200000 \mathrm{~m}^{3}$ and the daily discharge of $\sum_{7}$ OPEs was $132.4 \mathrm{~g}$ (Liang et al., 2016). This was at the same level with Chengdu in which the average daily discharge capacity was $157.9 \mathrm{~g}$. The daily discharges of $\sum_{7} \mathrm{OPEs}$ in the rainy and non-rainy period of the WWTP in Chengdu were $245.6 \mathrm{~g}$ and $70.3 \mathrm{~g}$, respectively, which were higher than the daily discharge range of $\sum_{7}$ OPEs in the summer (8.4-59.4 g) of 9 WWTPs in Suzhou, but in range of $36.7-31561.2 \mathrm{~g}$ in winter (Sun et al., 2018). Compared with the data of individual OPEs compound (TBEP $12.4 \mathrm{~g}$, TCEP $9.3 \mathrm{~g}$, TCPP $11.9 \mathrm{~g}$, TPhP $0.6 \mathrm{~g}$, TDCPP $2.4 \mathrm{~g}$ ) in a WWTP with the $25000 \mathrm{~m}^{3}$ of daily sewage discharge in the Pearl River Delta (Zhang et al., 2015), the discharge amount of TBEP, TCEP and TCPP per $10000 \mathrm{~m}^{3}$ of effluent in Chengdu were lower than that from the Pearl River Delta, but the amount of TPhP and TDCPP were higher than that from the Pearl River Delta. The per capita contribution of OPEs was calculated based on the received amount and the result was $0.2 \mathrm{mg} /$ person/day in non-rainy period but 0.7 $\mathrm{mg} /$ person/day in the rainy period (Table 2). The average per capita contribution was $0.4 \mathrm{mg} /$ person/day, which was far lower than the daily load of OPEs in Australian wastewater in 2011 (about 2.1 mg/person/day) (O'Brien et al., 2015) and from a WWTP in New York State (Kim et al., 2017).

Table 2 Daily per capita contribution of OPEs in a WWTP in Chengdu /mg

\begin{tabular}{|lcccccccc|}
\hline Per capita emissions & TnBP & TCEP & TCPP & TDCPP & TPhP & TBEP & TEHP & $\sum_{7}$ OPEs \\
\hline Rainy period & 0.324 & 0.024 & 0.020 & 0.102 & 0.013 & 0.177 & 0.005 & 0.665 \\
\hline Non-rainy period & 0.023 & 0.011 & 0.011 & 0.067 & 0.005 & 0.047 & 0.002 & 0.164 \\
$\begin{array}{l}\text { Average per capita } \\
\text { emissions }\end{array}$ & 0.173 & 0.017 & 0.015 & 0.084 & 0.009 & 0.112 & 0.003 & 0.414 \\
\hline
\end{tabular}

The daily discharge level of $\sum_{7}$ OPEs of the WWTP in this study was in the middle level compared with that of the domestic developed cities. Although the amount of OPEs per capita for domestic production in the study area was lower than that of foreign countries, Chengdu has a permanent population of 16.33 million by the end of 2018 which meant that there may be a situation of low per capita but high total amount of OPEs emissions. With the continuous development of Chengdu's economy and the increase of population, the output of wastewater and waste in Chengdu would increase, and the load of OPEs in the sewage may also increase. Therefore, the total amount of OPEs emissions and its control in southwest China should be taken into consideration.

\section{Conclusion}

The level of $\Sigma_{7}$ OPEs in the WWTP was $406.3-1144.7 \mathrm{ng} / \mathrm{L}$, with the primary components of TBEP and TDCPP. The removal rate of TnBP, TDCPP and TBEP in the treatment process of the WWTP was relatively high, whereas it was difficult to remove TCEP, TCPP and TEHP. The insufficient removal of OPEs by the 
UV disinfection channel has been observed. How to improve the terminal UV disinfection process of WWTP to effectively remove OPEs and other organic pollutants deserves further study.

During rainy period, the level of $\Sigma_{7} \mathrm{OPEs}$ in the WWTP ranges from 512.7 to $6494.4 \mathrm{ng} / \mathrm{L}$, and the main pollutants were TnBP, TBEP and TDCPP, indicated that rain markedly increased the load of OPEs in the WWTP and the level in the effluent by road runoff. During the rainy period, proportion of TBEP increased significantly.

Compared with other studies, the concentration of OPEs in the effluent of WWTP was in the middle level, and the contribution of OPEs per capita per day in Chengdu was relatively low. However, during the shift of labour-intensive manufacturing from the coastal developed areas to inland regions, OPEs were widely used in industrial and manufacturing processes in southwest China. In addition, due to the large population and high growth rate of the OPEs production, the total amount of OPEs emissions and its control should be taken into consideration.

\section{Declarations}

Acknowledgements This work was financially supported by the National Natural Science Fund of China. (No.41773072)

Ethics approval and consent to participate[Not applicable

Consent for publication $\square$ Not applicable

Availability of data and materials[The datasets used and analysed during the current study are available from the corresponding author on reasonable request.

Competing interests[The authors declare that they have no competing interests

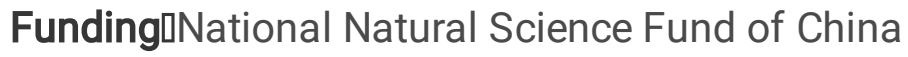

\section{Authors' contributions[}

Hongling Yin: Conceptualization, Methodology, Resources, Visualization, Writing-Review and Editing, Funding acquisition

Yi Luo: Sampling, Measurement, Data Analysis, Writing- Original Draft

Jiaojiao Song: Data Analysis, Writing- Review and Editing

Shiping Li: Data Analysis, Visualization

Shuyu Lin: Sampling, Investigation

Yuanming Xiong: Sampling, Investigation 
Shuhong Fang: Writing-Review, Visualization

Juan Tang: Sampling, Investigation

Acknowledgements囚This work was financially supported by the National Natural Science Fund of China. (No.41773072)

\section{References}

Ai R., 2013. 'Study on the treatment of two kinds of chlorinated org-anic phosphate simulated wastewater by UV/ $\mathrm{H}_{2} \mathrm{O}_{2}$. Wuhan Textil-e University.

Andresen, J. A., Grundmann, A., Bester, K., 2004. 'Organophosphorus flame retardants and plasticisers i-n surface waters. Sci. Total Env-iron. 332, 155-166. doi: 10.1016/j.scitotenv.2004.04.021

Bacaloni, A., Cucci, F., Guarino, C., Nazzari, M., Samperi, R., Aldo Laganà., 2008. 'Occurrence of organophosphorus flame retardant a-nd plasticizers in three volcanic lakes of central Italy. Environ. Sci. Technol. 42, 1898-1903. doi:10.1021/es702549g

Bester K., 2006. 'Personal care comp-ounds in the environment: pathways, fate, and methods for determination. J. Environ. Qual. 36, 1926. doi:10.2134/jeq2007.0016br

Bollmann, U. E., MLler, A., Xie, Z., Ebinghaus, R., Jürgen W. E., 2012. 'Occurrence and fate of organophosphorus flame retardants and plasticizers in coastal and m-arine surface waters. Water Res. 46, 0538. doi:10.1016/j.watres.2011.11.028

Gao, X. Z., Xu, Y. P., Wang, Z. J., 2015. 'Progress in environment e-xposure, transport and transform of organophosphorus flame rtard-ants. Asian J. Ecotoxicol. 10, 56-68.

Gao L H., 2016. 'Study on pollution level and distribution characteris-tics of organic phosphates in ur-ban environment of Beijing. Beij-ing University of Science and Technology.

Gao, L. H., Li, W. H., Shi, Y. L., Liu, J. M., Cai, Y. Q., 2014. 'Ana-lytical methods and pollution sta-tus of organophosphate flame re-tardants. Environmental Chemis. 33, 1750-1761.

Gnecco, I., Berretta, C., Lanza, L. G., Barbera, P. L., 2005. 'Storm wa-ter pollution in the urban enviro-nment of Genoa, Italy. Atmosph-eric Res. 77, 0-73. doi:10.1016/j.atmosres.2004.10.017

Gromaire, M. C., Garnaud, S., Saad, M., Chebbo, G., 2001. 'Contribut-ion of different sources to the pollution of wet weather flows in combined sewers. Water Res. 35, 0-533. doi:10.1016/s00431354(00)00261-x.

Guo, J., Romanak, K., Westenbroek, S., Hites, R. A., Venier, M., 2017. 'Current-use flame retardants i-n the water of Lake Michigan t-ributaries. Environ. Sci. Technol. 51, 9960-9969. doi: 10.1021/acs.est.7b01294 
Hou, P. Q., Ren, Y. F., Wang, X. K., Ouyang, Z. Y., Zhou, X. P., 2012. 'Research on evaluation of water quality of Beijing urban st-ormwater runoff. Environmental Sci. 1, 71-75. doi: 10.13227/j.hjkx.2012.01.025

Javier, C., Belén, G., Pizarro, M., Piz-arro, M., Casal, P., Pizarro-Álvarez, C., Dachs, J., 2016. 'Organophosphate ester flame retardantsand plasticizers in the global oc-eanic atmosphere. Environ. Sci. Technol. 50. doi:10.1021/acs.est.6b04344

Jing, H. W., Hua, L., Chen, Y. Y., Shan, W. J., Shi, W. X., Huang, Z. F., Jiao, Z. Z., 2012. 'Polluti-on characteristics of runoff in ur-ban storm sewer and its impacti-on to receiving water. Environm-ental Chemis. 31, 208-215.

Kim, U. J., Kannan, K., 2018. 'Occu-rrence and distribution of organ-ophosphate flame retardants/plasticizers in surface waters, tap wat-er, and rainwater: implications f-or human exposure. Environ. Sc-i. Technol. 52, 5625-5633. doi: 10.1021/acs.est.8b00727

Kim, U. J., Oh, J. K., Kannan, K., 2017. 'Occurrence, removal and e-nvironmental emission of organophosphate flame retardants/plasti-cizers in a wastewater treatment plant in New York State, Usa. Environ. Sci. Technol. 51, 7872-7880. doi:10.1021/acs.est.7b02035

Lee, J. H., Bang, K. W., Ketchum, L. H., Choe, J. S., Yu, M. J., 2002. 'First flush analysis of urban storm runoff. Sci. Total Environ. 293, 163-175. doi:10.1016/s0048-9697(02)00006-2

Li, D., Zhang, S. H., Zhang, Q., Wa-ng, B., Pu, Y. Q., Zhao, X., Li, H., Song, N.H., Guo, R.X., 2019. 'Occurrence and risk assessme-nt of organophosphate esters in source water of the Nanjing sect-ion of the Yangtze River. Envir-onmental Sci. 20, 205-212. doi:10.13227/j.hjkx.201907149

Liang, K., Liu, J., 2016. 'Understandi-ng the distribution, degradation and fate of organophosphate este-rs in an advanced municipal se-wage treatment plant based on mass flow and mass balance ana-lysis. Sci. Total Environ. 544, 262-270. doi: 10.1016/j.scitotenv.2015.11.112.

Liu, Q., 2018. 'Distribution of organo-phosphate flame retardants amon-g multi-media in Minjiang river basin. Chengdu University of In-formation Technology.

Marklund, A., Andersson, B., Haglun-d, P., 2005. 'Organophosphorus f-lame retardants and plasticizers in Swedish sewage treatment pla-nts. Environ. Sci. Technol. 39, 7423-7429. doi:10.1021/es051013l

Meyer, J., Bester, K., 2004. 'Organop-hosphate flame retardants and pl-asticisers in wastewater treatmen-t plants. J. Environ. Monit. 6, 599-605. doi:10.1039/b403206c

Nicklas, Paxéus., 1996. 'Organic poll-utants in the effluents of large w-astewater treatment plants in Sweden. Water Res. 30, 0-1122. do-i:10.1016/0043-1354(95)00278-2

O'Brien, J. W., Thai, P. K., Brandsma, S. H., Leonards, P. E. G., Ort, C., Mueller, J. F., 2015. 'Wastew-ater analysis of census day sam-ples to investigate per capita in-put of organophosphorus flame r-etardants 
and plasticizers into wa-stewater. Chemosphere 138, 328-334. doi:10.1016/j.chemosphere.2015.06.014.

Pang, L., Zhang, X. J., Pang, R., Zhao, J. H., Zhang, H. Z., 2016. 'Removal of organophosphate este-rs in municipal wastewater treat-ment process. Journal of Henan Normal. 44, 98-103. doi:

10.16366/j.cnki.1000-2367.2016.03.019

Perdikaki, K., Mason, C. F., 1999. 'I-mpact of road run-off on receiv-ing streams in eastern england. Water Res. 33, 0-1633. doi:10.1016/s0043-1354(98)00396-0

Prsch, J., Pansch, G., Puchert, W., 2002. 'Vorkommen von TCEP und TCPP in Badeseen sowie in Hausbrunnen Indlicher Gebiete Mec-klenburg-Vorpommerns, Vom Was-ser. Environ. Sci. Pollut. Res. 98, 159164. doi: https://doi.org/10.1007/s11356-009-0169-6

Quintana, J. B., Rodil, R., Reemtsma, T., 2006. 'Determination of pho-sphoric acid mono-and diesters i-n municipal wastewater by solid-phase extraction and ion-pair liq-uid chromatography-tandem mas-s spectrometry. Anal Chem 78, 1644-1650. doi:10.1021/ac0517186

Reemtsma, T., Weiss, S., Mueller, J., Petrovic, M., González, S., Barce-lo, D., 2006. 'Polar pollutants e-ntry into the water cycle by mu-nicipal wastewater: a European perspective. Environ. Sci. Techno-I. 40, 54515458. doi:10.1021/es060908a

Regnery, J., Püttmann, W., 2009. 'Or-ganophosphorus flame retardants and plasticizers in rain and snow from middle Germany. CLEAN-Soil, Air, Water. 37, 334-342. do-i:10.1002/clen.200900050

Ren, Y.F., Wang, X.K., Ouyang, Z. Y., Zheng, H., Duan, X. N., Mia-o, H., 2008. 'Stormwater runoff-quality from different surface in an urban catchment in Beijing, China. Water Environ. Res. 80, 719-724.doi:

$10.2175 / 106143008 \times 276660$

Rodgers, T. F. M., Truong, J. W., Jan-tunen, L. M., Helm, P. A., Dia-mond, M. L., 2018. 'Organophos-phate ester transport, fate, and e-missions in toronto, canada, esti-mated using an updated multimedia urban model. Environ. Sci. T-echnol. 52, 12465-12474. doi:10.1021/acs.est.8b02576

Schindler, B. K., F, Rster, K., Jürgen, Angerer., 2009. 'Determination of human urinary organophosphat-e flame retardant metabolites bysolid-phase extraction and gas c-hromatography-tandem mass spectrometry. J. Chromatogr. B: Ana-I. Technol. Biomed. Life Sci. 877, 375-381.

doi:10.1016/j.jchromb.2008.12.030

Shi, Y. L., Gao, L. H., Li, W. H., W-ang, Y., Liu, J. M., Cai, Y. Q., 2016. 'Occurrence, distribution and seasonal variation of organo-phosphate flame retardants and p-lasticizers in urban surface wate-r in beijing, china. Environ. Pol-lut. 209, 1-10. doi:10.1016/j.envpol.2015.11.008

Strobel, A., Letcher, R. J., Willmore, W. G., Sonne, C., Dietz, R., 2018. 'Structure-dependent in vitro metabolism of alkyl-substituted a-nalogues of triphenyl phosphate in East Greenland polar bears an-d ringed seals. Environ. Sci. Te-chnol. Letters. 5, 214-219. doi:10.1021/acs.estlett.8b00064 
Sun J.W., 2018. 'Pollution distribution characteristics of organophosphorus flame retardant and plasticize-r in sewage and sludge of sewa-ge treatment plant. Suzhou Univ-ersity of science and technology.

Sundkvist, A. M., Olofsson, U., Hagl-und, P., 2010. 'Organophosphoru-s flame retardants and plasticize-rs in marine and fresh water bi-ota and in human milk. J. Envir-on. Monit. 12, 943. doi:10.1039/b921910b

Taebi, A., Droste, R. L., 2004. 'First flush pollution load of urban st-ormwater runoff. J. Environ. En-g. Sci. 3, 301-309. doi:10.1139/s04-018

Tan, H., Peng, C., Guo, Y., Wang, X., Wu, Y., Chen, D., 2017. 'Organ-ophosphate flame retardants in h-ouse dust from south china and related human exposure risks. B-ull. Environ. Contam. Toxicol. 99, 334-349. doi:10.1007/s00128-017-2120-8

Thomas, H., Andy, M., Britta, F., An-drea, K., Gudrun, M., Asaf, P., Birgit F., 2004. 'Field studies onthe fate and transport of pharma-ceutical residues in bank filtratio-n. Ground Water Monit. Rem. 24, 70-77. doi:10.1111/j.1745-6592.2004.tb00714.x

Wan, W., Huang, H., Lv, J., Han, R., Zhang, S., 2017. 'Uptake, transl-ocation, and biotransformation o-f organophosphorus esters in wh-eat (triticum aestivum I.). Envir-on. Sci. Technol. 51, 13649-13658. doi:10.1021/acs.est.7b01758

Wang, X. L., Zhu, L.Y., Zhong, W. J., Yang, L. P., 2018. 'Partition and source identification of organophosphate esters in the water and sediment of Taihu Lake, Chi-na. J. Hazard. Mater. 360, 43-50. doi:10.1016/j.jhazmat.2018.07.082

Wei, G.L., Li, D. Q., Zhuo, M. N., Liao, Y. S., Xie, Z. Y., Guo, T. L., 2015. 'Organophosphorus fla-me retardants and plasticizers: so-urces, occurrence, toxicity and h-uman exposure. Environ. Pollut. 196, 29-46. doi:10.1016/j.envpol.2014.09.012

Weigel, S., Bester, K., Heinrich, Hüh-nerfuss., 2005. 'Identification and quantification of pesticides, industrial chemicals, and organobrom-ine compounds of medium to hi-gh polarity in the North sea. M-ar. Pollut. Bull. 50, 252-63. doi:10.1016/j.marpolbul.2004.10.011

Yang, Z. H., He, M. J., Yang, T., Lu, J. F., Wei, S. Q., 2018. 'Occurr-ence and distribution of the organophosphate esters in soils of mixed-land use area in Chongqin-g city. Environmental Sci. 39, 51355141. doi:10.13227/j.hjkx.201803191

Yin, H. L., Li, S. P., Ye, Z. X., Yang, Y. C., Liang, J. F., You, J. J., 2015. 'Pollution level and sourc-es of organic phosphorus esters in airborne $\mathrm{PM}_{2.5}$ in Chengdu Ci-ty. Environmental Sci. 36, 3566-3572. doi:

10.13227/j.hjkx.2015.10.003 
Yin, H. L., Li, S. P., Ye, Z. X., Lian-g, J. F., You, J. J., 2016. 'Pollu-tion characteristics and sources of OPEs in the soil of Chengducity. Acta Scientiae Circumstantiae. 36, 606-613. doi:10.13671/j.hjkxxb.2015.0489

Yin , H. L., Liu, Q., Deng, X., Liu, X. W., Fang, S. H., Xiong, Y. M., Song, J. J., 2021. 'Organophosph-ates (OPEs) in water, suspended particulate matter (SPM) and sedi-ments of the Minjiang River, Chi-na Chinese Chemical Letters. doi:10.1016/j.cclet.2021.02.023.

Yin, H. L., Liang J. F., Wu, D., Li, S. P., Luo, Y., Deng, X., 2020. 'Measurement report: Seasonal, dist-ribution and sources of organoph-osphate esters in $\mathrm{PM}_{2.5}$ from an i-nland urban city in southwest Chi-na. Atmos. Chem. Phys., 20, 14933-14945. doi:10.5194/acp-2020-329

Zhang, H., Wang, Y., Liu, P., Li, Y., Yang, H., An, T., 2015. 'The oc-currence and removal of organop-hosphate ester flame retardants/p-lasticizers in a municipal waste-water treatment plant in the pear-l river delta, china. J. Environ. Sci. Health, Part A: Toxic/Hazard. Subst. Environ. Eng. 50, 1291-1297.

doi:10.1080/10934529.2015.1055158

Zhang, Q. Q., Li, X. Q., Wang, X. K., Wan, W. X., Ouyang, Z. Y., 2014. 'Research advance in the characterization and source appor-tionment of pollutants in urban roadway runoff. Ecology and Environmental Sciences. 23, 352-358. doi:10.16258/j.cnki.1674-5906.2014.02.020

Zhang, Y. G., Hu, Y. J., Ma, Y. M., Ning, P, S., Cai, Y. Y., 2012. 'Market analysis and prospect of phosphate flame retardant. Therm-osetting Resin. 27, 73-77. doi:10.13650/j.cnki.rgxsz.2012.06.015

Zhao, S., Liu, S. L., Zhang, H., Qiu, Y. L., Zhu, Z. L., Zhao, J. F., 2018. 'Removal efficiency of organophosphate esters in wastewat-er treatment processes. China W-ater Wastewater. 34, 88-91. doi:10.19853/j.zgjsps.1000-4602.2018.05.018

\section{Figures}

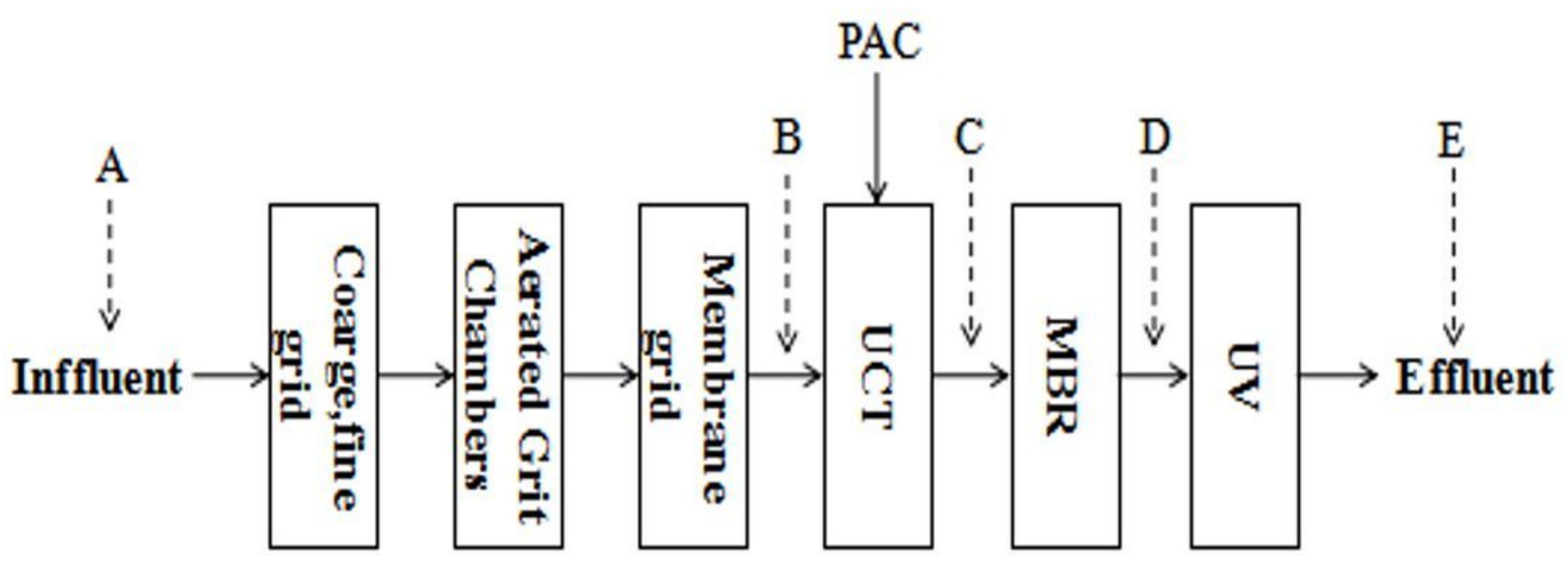


Figure 1

Treatment process and sampling site in WWTP

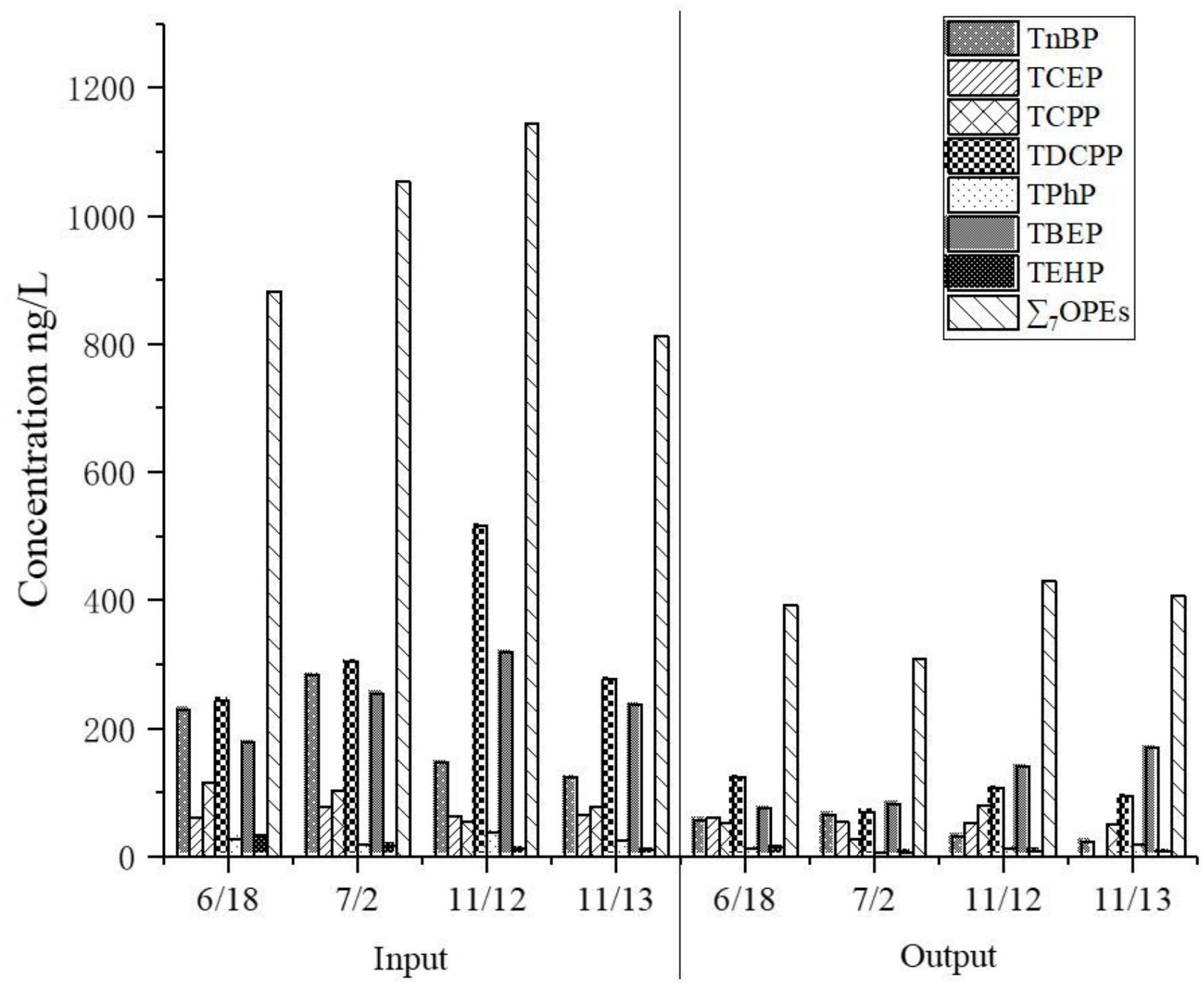

Figure 2

Daily variation of $\sum 70 P E s$ concentrations in WWTP 


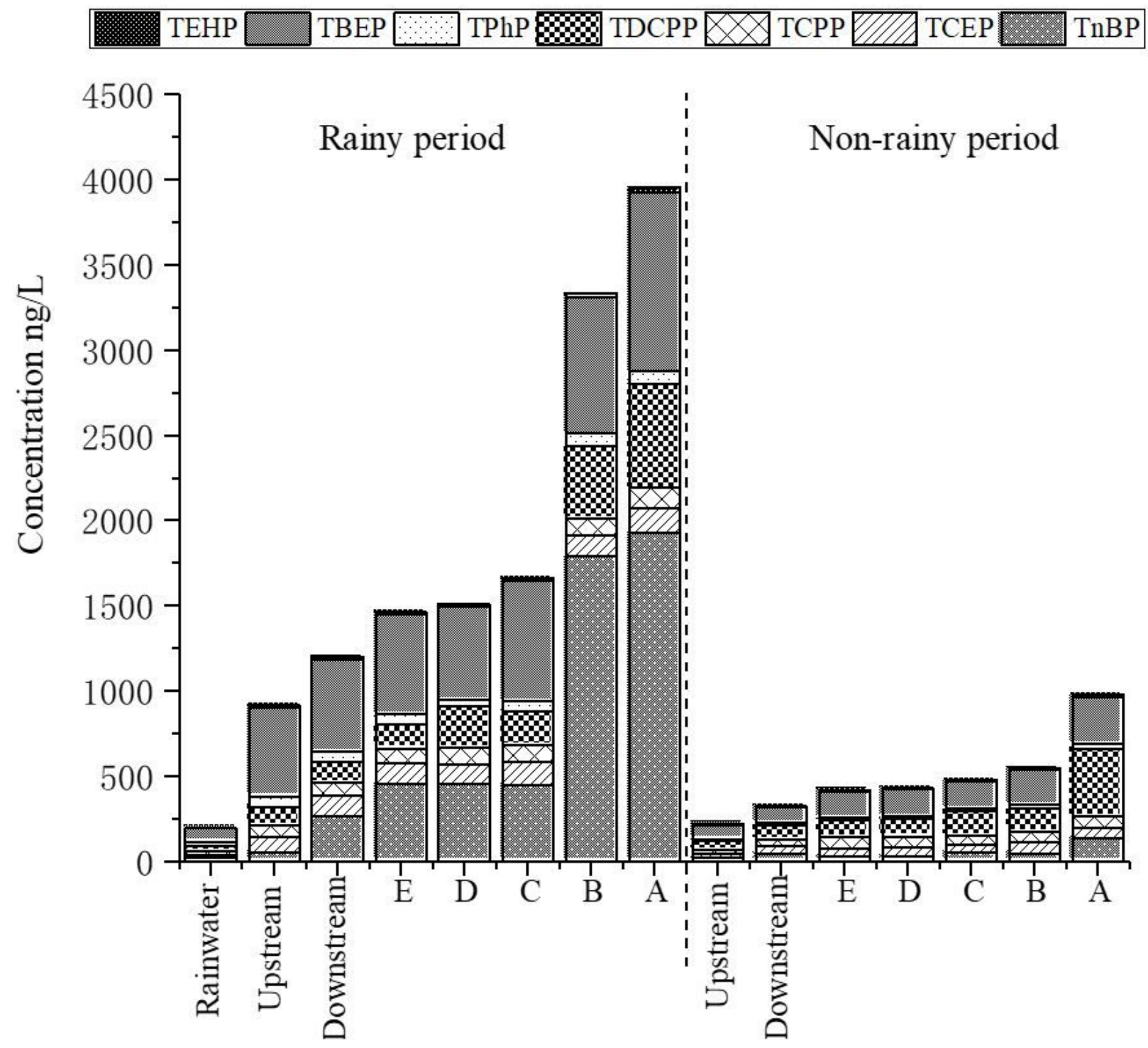

Figure 3

Concentrations and composition profiles of OPEs in WWTP and receiving water 


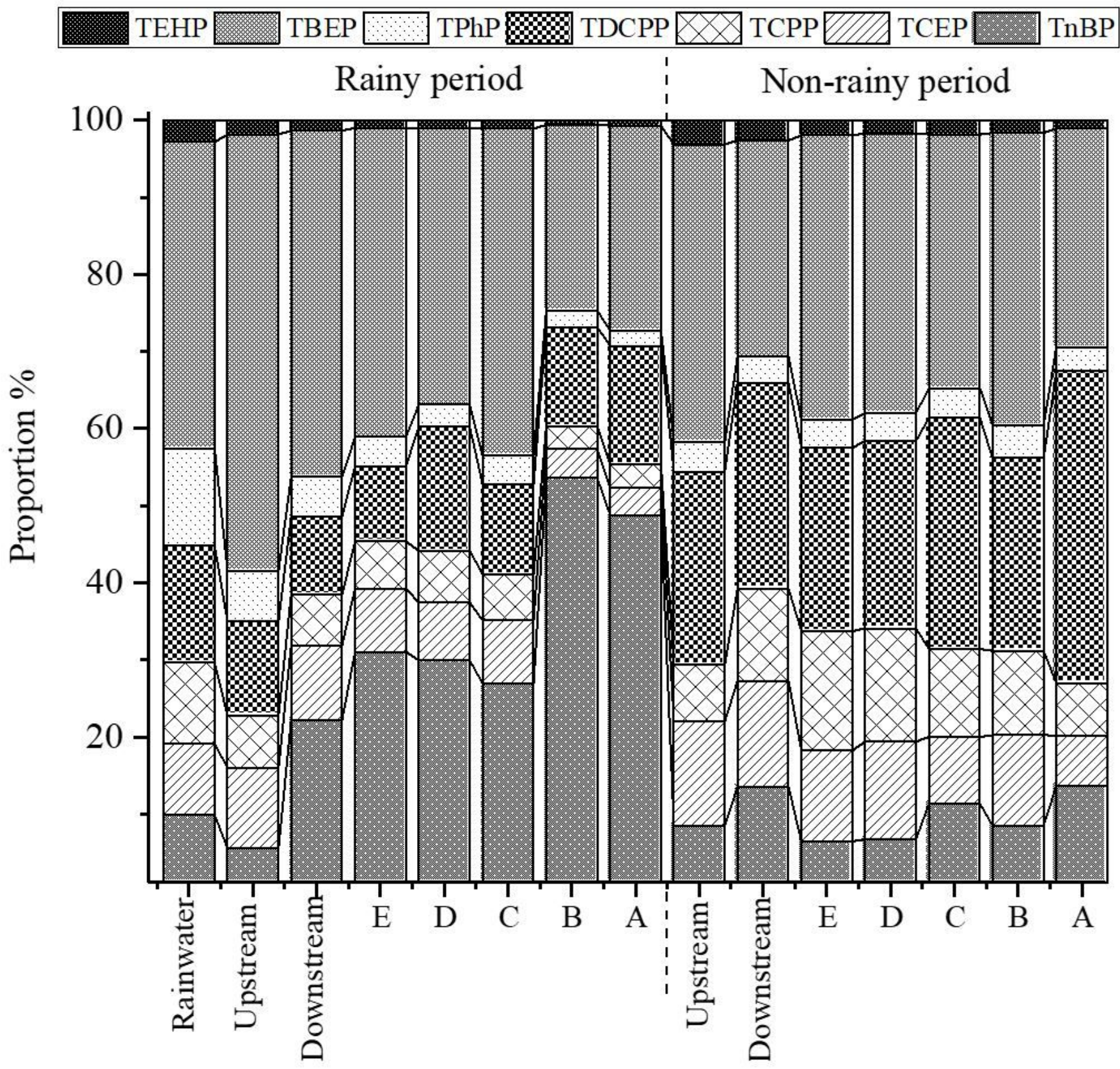

Figure 4

Distribution of individual OPEs in WWTP and receiving river 


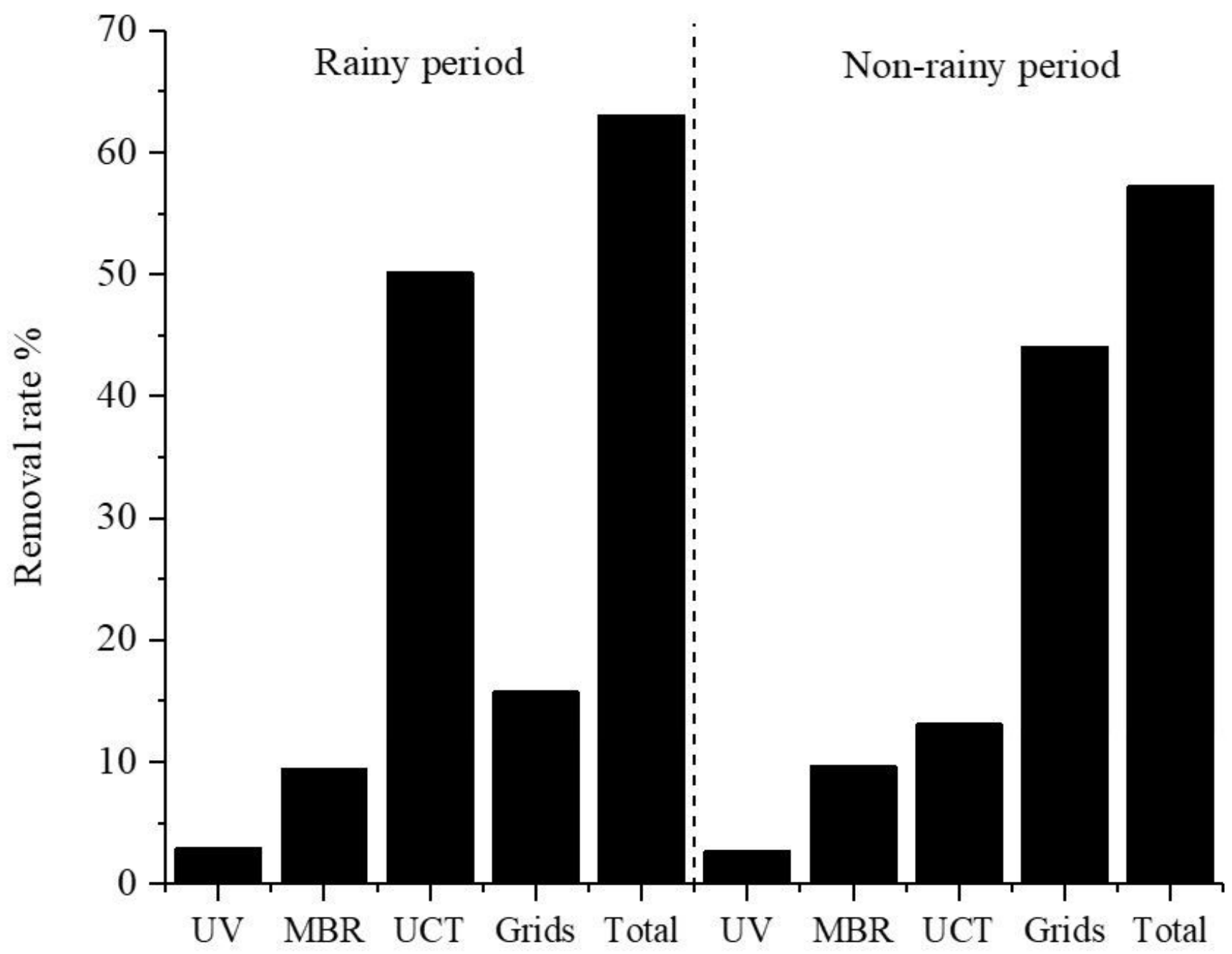

Figure 5

Total removal rate of $\sum$ 70PEs in WWTP 


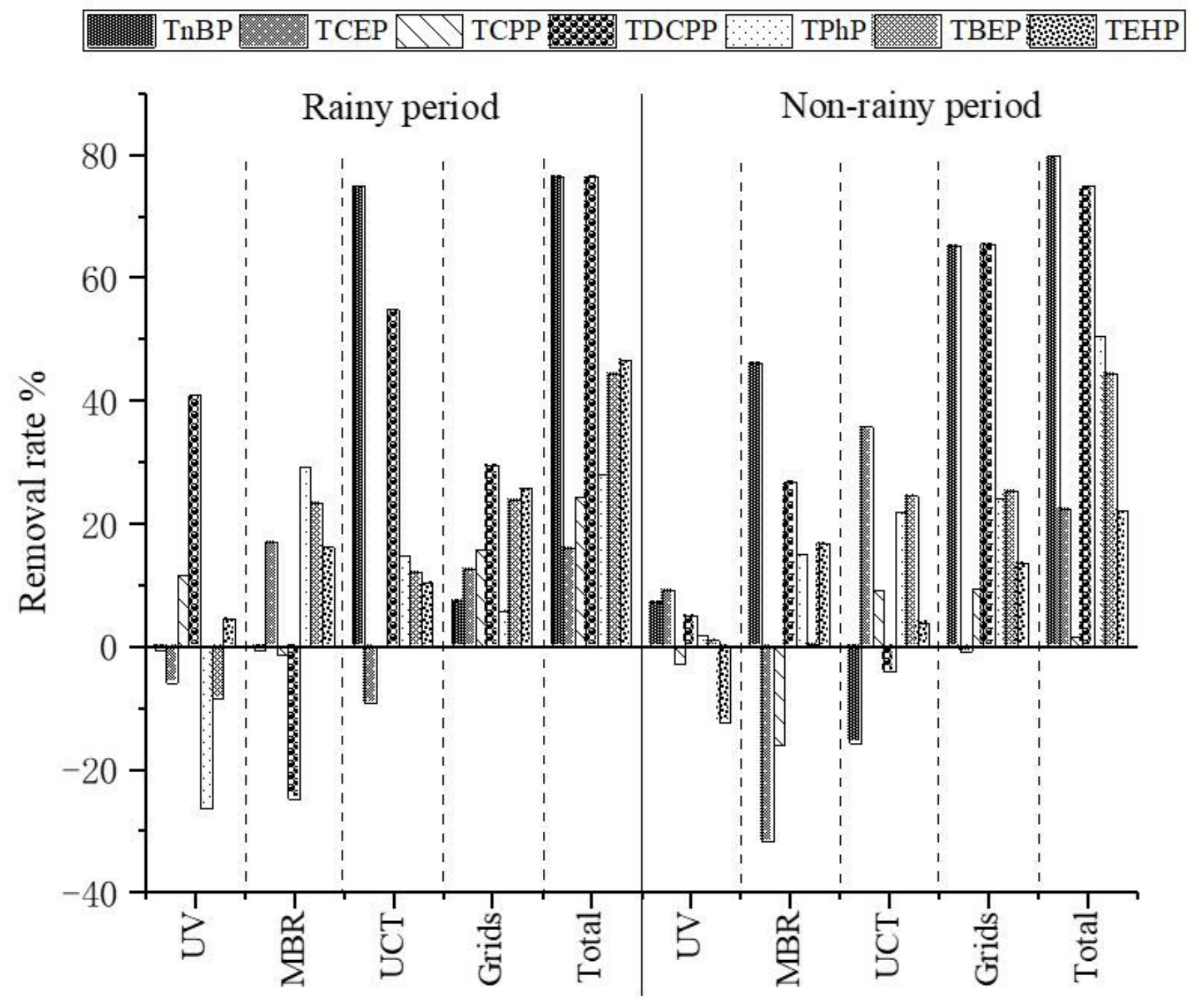

Figure 6

Removal rate of individual OPEs compound in WWTP 